\title{
Characterization of Coatings with Ions and Electrons
}

Lucille A. Giannuzzi ${ }^{1}$, Noel S. Smith ${ }^{2}$, and Sanjay Sampath ${ }^{3}$

1. L.A. Giannuzzi \& Associates LLC, 12580 Walden Run Dr., Fort Myers, FL 33913 USA

2. Oregon Physics, LLC, 19075 NW Tanasbourne Dr., Suite 150, Hillsboro, OR 97124 USA

3. Stony Brook University, Materials Science and Engineering Dept., Center for Thermal Spray Research, Stony Brook, NY 11974 USA

Focused ion beam (FIB) instruments allow for site specific sectioning with little to no initial sample preparation [1]. $\mathrm{Ga}^{+}$based liquid metal ion source FIBs provide as small as sub $10 \mathrm{~nm}$ milling and imaging resolution [1], while $\mathrm{Xe}^{+}$based inductively coupled plasma FIBs (PFIBs) can operate at high beam currents advantageous for large area milling [2,3]. Ion-induced secondary electron imaging may be used to discern different materials or phases [4] or grain size via channeling contrast [5]. Either of these FIB systems may be used to create sections for direct examination by the ion beam, scanning electron microscopy or transmission electron microscopy $[1,6]$. These advanced techniques have been used to evaluate several types of coatings over the years with great success. Giannuzzi et al. have studied thermal barrier coatings [7, 8], environmental barrier coatings [9], dental implant coatings [10,11] and plasma spray coatings [12].

FIG. 1 and FIG. 2 show how large area milling with a PFIB can be used to create large area cross-sections for morphological and microstructural analysis of plasma spray coatings. FIG. 1 shows a $300 \mu \mathrm{m}$ wide Xe $\mathrm{e}^{+}$PFIB section of a $300 \mu \mathrm{m}$ thick plasma sprayed Mo coating deposited on an Al-alloy substrate and imaged using secondary electrons induced from a $\mathrm{Ga}^{+}$FIB. FIG. 2 shows $\mathrm{Ga}^{+}$FIB induced secondary electron images of $\mathrm{Xe}^{+}$PFIB sections. In FIG. 2(a) ion channeling contrast reveals columnar grain structure within several splats of the plasma spray coated Mo. In FIG. 2(b) both ion channeling contrast and material contrast shows details within the Mo coating and the Al-alloy substrate interface.

References

[1] L.A. Giannuzzi and F.A. Stevie (eds.) Introduction to Focused Ion Beams (2005) Springer.

[2] N.S. Smith et al., J. Vac. Sci. Technol. B 24(6) (2006) 2902-2906.

[3] Paul Tesch et al., ISTFA, ASM International (2008) 7-13.

[4] L.A. Giannuzzi and M. Utlaut, Ultramicroscopy, 11 (2011) 1564-1573.

[5] L.A. Giannuzzi and J.R. Michael, in press, Microscopy and Microanalysis (2013).

[6] L Giannuzzi and N Smith, Microsc. and Microanal. 17(S2) (2011) 646-647.

[7] Altaf H. Carim et al., Materials Science and Engineering A334 (2002) 65-72.

[8] S. Laxman, et al., Surface and Coatings Technology 177-178 (2004) 121-130.

[9] C.H. Henager Jr. et al., Journal of Nuclear Materials 367-370 (2007) 1139-1143.

[10] Lucille A. Giannuzzi et al., Journal of Maxillofacial Surgery April 65:4 (2007) 737-747.

[11] Lucille A. Giannuzzi in Implant Dentistry Research Guide, ed. A. Ballo, (2012) Nova 343-352.

[12] Yuhong Wu et al., Mater. Res. Soc. Symp. Proc. 983 (2007) 0983-LL04-04-KK04-04. 


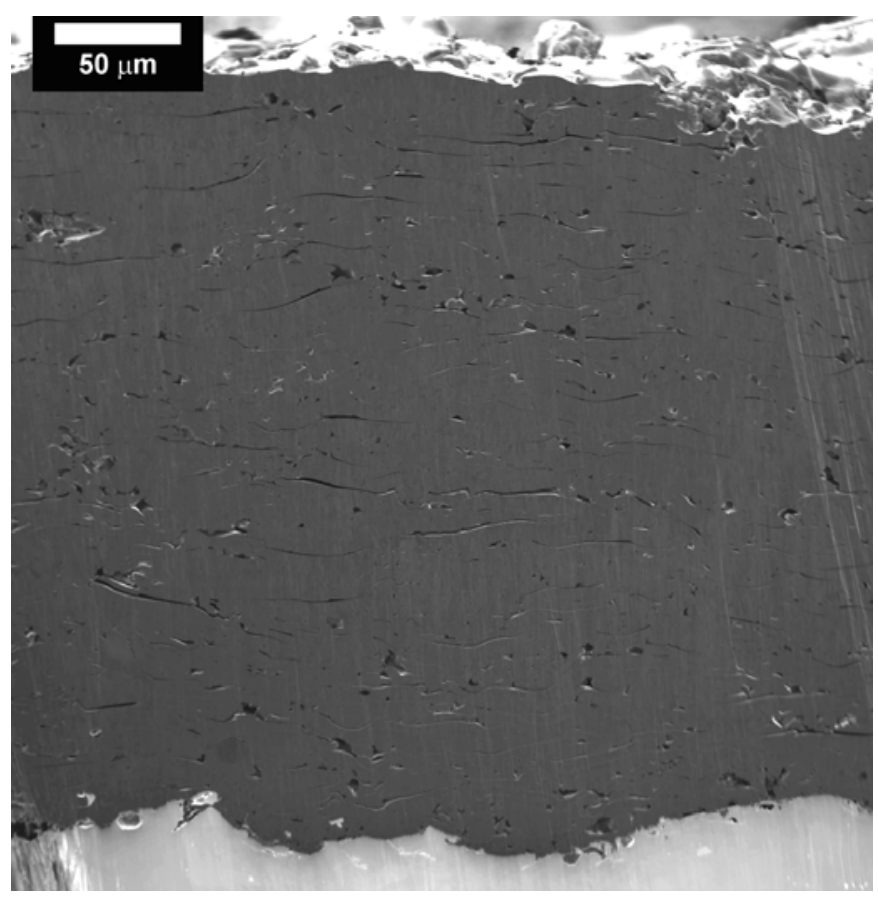

FIG. 1. Plasma sprayed Mo coating on an Al-alloy substrate sectioned with a Xe+ PFIB and imaged with a $\mathrm{Ga}^{+}$FIB.

(a)

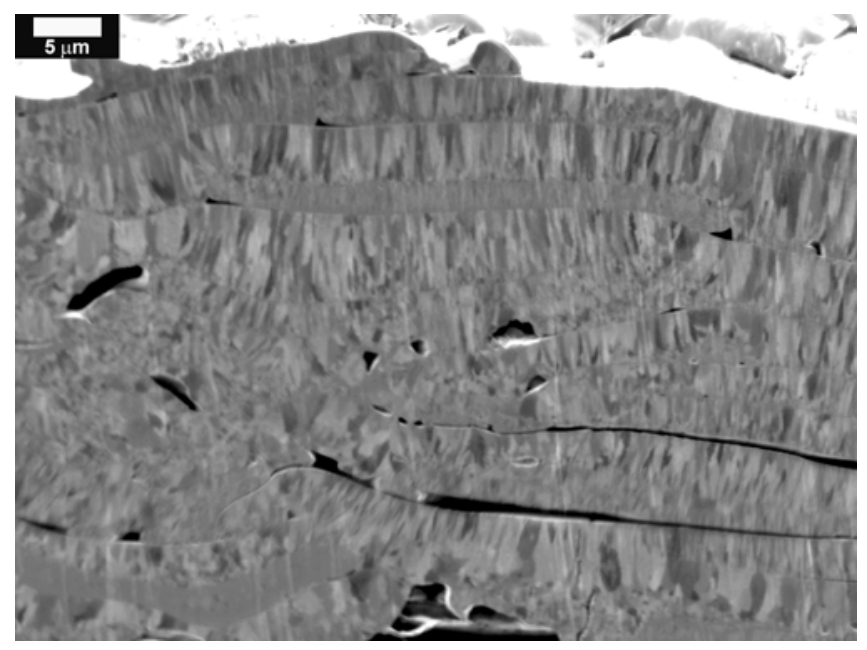

(b)

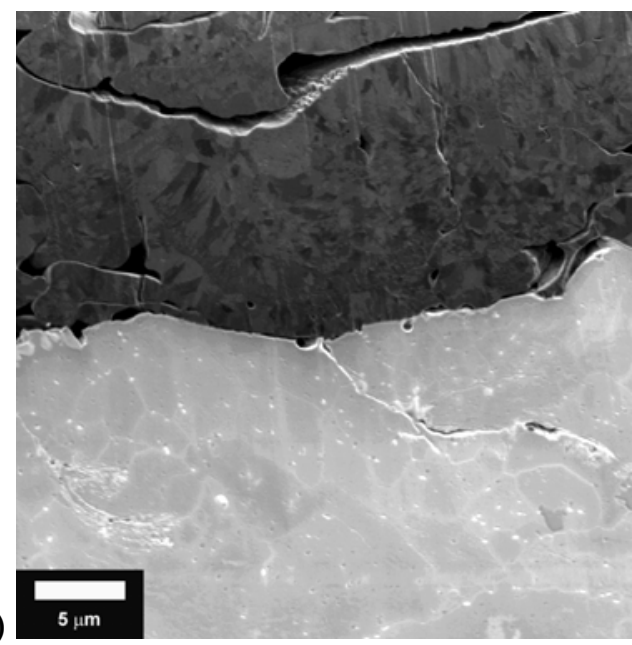

FIG. 2. $\mathrm{Ga}^{+}$FIB induced secondary electron images of $\mathrm{Xe}^{+}$PFIB sections. (a) Ion channeling contrast showing columnar grain structure within the plasma spray coating Mo. (b) Ion channeling and material contrast showing the Mo coating and Al-alloy substrate interface. 